\title{
A FORMAÇÃO DA LINGUAGEM COMUNICATIVA EM HABERMAS: POSSIBILIDADES NA EMANCIPAÇÃO DA EDUCAÇÃO
}

Resumo: A partir da Teoria Crítica de Habermas é possível desenvolver, no campo educacional, relações entre conhecimento e interesse. Iminente a isso, surge novas teorias humanas por se tratar de uma perspectiva comunicativa e livre na relação entre sujeitos. É neste entendimento do agir comunicativo num ambiente de competência de cooperação e linguagem, que buscamos argumentos críticos a fim de reconstruir o entendimento na perspectiva da emancipação da educação. Com isso, o sentido da educação passa ser um processo social emancipativo, pois estaria unindo a linguagem da ação comunicativa a práxis do ensinar. Esta possibilidade colocaria os sujeitos da ação comunicativa em igualdade para analisar os pressupostos epistemológicos que versam os processos educacionais.

Palavras - chave: Ação comunicativa; Formação docente; Educação

The formation of linguage communicative in Habermas: possibilities in the emancipation of education

Abstract: On the bases of Habermas' Critical Theory it was possible to develop, within the educational field, relationships between knowledge and interest. In the imminence of that, new human theories emerge for being that a question of an open and communicative perspective in the relationship amongst individuals. It is in this understanding of the communicative acting, within an environment of competence, communication and language, that we search for critical arguments in order to reconstruct the understanding in the perspective of the emancipation of education. Thus, the sense of education starts being an emancipative social process because it would be uniting the language of communicative action to the praxis of teaching. This possibility would put the individuals of the communicative action in equality to analyze the epistemological presuppositions that deals with the educational processes.

Keywords: Communicative action, teaching formation, education.

\footnotetext{
${ }^{1}$ Licenciado em Filosofia e Mestrado em Educação pela Universidade Federal de Santa Maria. Doutorado em Educação pela Universidade Federal de São Carlos. E-mail: E-mail: elvis.furquim01@gmail.com.
} 


\section{Revista Ibero-Americana de Humanidades, Ciências e Educação \\ Produção e democratização do conhecimento na Ibero-América}

\section{INTRODUÇÃO}

A cultura tornada hegemônica visa a se contrapor à esfera pública, porque ao contrário da formação da vontade coletiva, a opinião não é esclarecida democraticamente. A formação do debate visa proporcionar um ambiente de agir e falar sem coações que pode auxiliar a educação. Surge então a instância da racionalidade da linguagem intersubjetiva e comunicativa, que articula o ego que se encontra numa relação interpessoal. Essa proposta busca repensar criticamente a prática educativa nos processos pedagógicos. É com possibilidade de restaurar da razão abrangente que tentaremos identificar, no discurso de Habermas, o potencial cognitivo da linguagem comunicativa que serve de suporte teórico, repensando os "fundamentos da educação".

A tradição da história cultural procede de maneira a provocar o processo de desvelar os valores da vida na perspectiva dos participantes no desenvolvimento de interações. O lócus pré- interpretativo pode revelar o sentido teórico na esfera do ensino, pois, operar no passado no sentido de reconstrução teórica dos aspectos formativos pode significar uma contribuição pedagógica no ambiente de formação. É nessa perspectiva que Pinto (1996) diz, acerca da educação, que não se pode educar para o futuro sem se instruir no processo de ensino-aprendizagem sobre o passado. Por este viés, Forquim (1993, p. 10) comenta que "a educação é cada vez menos capaz, hoje em dia, de encontrar um fundamento de uma legitimação de ordem cultural, porque a cultura perdeu seu norte e se encontra privada das amarras da tradição e da direção do princípio da autoridade". Encontrar uma referência segura não é o propósito fundamental da cultura contemporânea, pois o ensino encontra se acabrunhado pelas múltiplas manifestações culturais e autoritárias da razão e, é possível acrescentar também, por causa da ausência de base conceitual da tradição.

O processo de se educar não é dado muitas vezes à relevância no sentido de ser uma ação cultural múltipla da tradição, que se preocupa em reaproximar o pensamento contemporâneo dos ideais da idade clássica. A situação se configura como um afastamento da essência da "natureza humana" que se praticava ou se produzia no curso da história da tradição, visto que o sentido do 


\section{Revista Ibero-Americana de Humanidades, Ciências e Educação \\ Produção e democratização do conhecimento na Ibero-América}

ensino, por exemplo, é substituído por pensamentos velozes e transitórios da cultura do imediatismo. Em vista desse entendimento, Arendt (1992) diz que a problemática da educação conecta à crise da autoridade, no sentido de criar uma situação crítica, pois não se busca mais vivenciar as experiências verdadeiras e incontestáveis, como a quebra do princípio da autoridade e de valorização das grandes obras do passado que foram fundamentais ao longo do processo de formação humana.

Em consequência disso, o processo de reconstrução na tradição pedagógica se dá de maneira instantânea e, com isso, a tendência é provocar a instabilidade na cultura hodierna, incitando o processo de irreflexão no direito e a liberdade de repensar o ensino. Entretanto, a proposta da ação comunicativa habermasiana procura se expressar a partir da linguagem que busca entender as bases universais voltadas para a comunicação entre os interlocultores, pois é regida pelo cenário amplo que compete à transmissão de questões fundamentais da educação.

Pressupõe-se que essa linguagem de comunicação pública é considerada uma fonte inesgotável nos debates que envolvem a aprendizagem. É um diálogo sempre aberto a argumentos inesperados, no qual novas teorias humanas podem surgir a qualquer momento, já que é uma perspectiva comunicativa e livre. O processo comunicativo se encontra no nível da racionalidade da linguagem que tem a pretensão de almejar a evolução social, cultural e, também educativa.

Dessa forma, pensamos que a busca pelo sentido da educação é um processo social, transformador, com ideal emancipativo, sob a condição e a possibilidade de serem construídos ou reconstruídos argumentos em grupos de pessoas que participam democraticamente do processo. Nesse entendimento pluralizado, o desenvolvimento pedagógico mediado por uma linguagem intersubjetiva almeja o entendimento consensual entre sujeitos. No entanto, a ideia de um possível acordo é muitas vezes despercebida pelos profissionais da educação, por entender que seja uma mera idealização e por acreditar na ineficácia de responder às expectativas da formação pedagógica naquele 


\section{Revista Ibero-Americana de Humanidades, Ciências e Educação \\ Produção e democratização do conhecimento na Ibero-América}

instante.

É possível que em algum momento ou fase da vida, por hipótese, o educador contemporâneo ouviu ou mesmo aprendeu que fazer educação leva tempo, já que o ensino deve ser entendido também como uma trajetória ascendente e imanente na constituição do gênero humano. A possibilidade de restauração cultural da tradição pretende ser entendida e respeitada na integridade, pois, do contrário, pode ocorrer o despreparo e se perder a sua "validade".

Nesse sentido, existe aí a possibilidade de valorizar não somente o aspecto intelectual de vivência solidária em sociedade, mas também os espaços culturais mais amplos possíveis de convivência social, costumes, lazer, história e outras formas de condutas de vida humana que constituem a evolução cultural. É nessa perspectiva que Habermas diz: "Para mim, cultura é o armazém de saber, do qual os participantes da comunicação extraem interpretações no momento em que se entendem mutuamente sobre algo" (2002, p.96). Nessa visão, a cultura é entendida como se fosse o núcleo da educação que abrange o âmbito mais variado e amplo possível da comunicação. Nessa expectativa de linguagem, a interpretação na realidade do mundo social e educacional é possível mediante o entendimento recíproco. É uma relação intersubjetiva por excelência e, por essa razão, revela as diversidades culturais que podem ser restauradas através da ação comunicativa e interpretativa.

Pensa-se que a educação deveria dar mais atenção à ideia de linguagem comunicativa, para ser reconstruída em seu desenvolvimento. No entanto, isso não quer dizer agir sem regras, pois as normas asseguram as condições necessárias à validade do processo de diálogo e aprendizagem. É neste entendimento que Habermas salienta na teoria do agir comunicativo, visto que é uma reconstrução de relações humanas pela via comunicativa da competência de cooperação e linguagem.

Unir a linguagem da ação comunicativa ao ensino consiste na crítica ao processo emancipativo intelectual em nível epistemológico. Sem dúvida, esse é um dos diagnósticos críticos vividos pela educação, visto que a perda da tradição 


\title{
Revista Ibero-Americana de Humanidades, Ciências e Educação \\ Produção e democratização do conhecimento na Ibero-América
}

da história pedagógica, conjugada com a proliferação da modernização, são modos exteriores do uso da razão técnica e objetivista, dando a ilusão de que eles são processos de aprendizagem pedagógica.

A possibilidade da linguagem comunicativa de articular saberes na esfera pública permite capacitar, orientar, organizar, negociar, dialogar, criticar, concordar, discordar, conversar, ouvir, entre outras, as atitudes que atuam em diferentes espaços de comunicação social e educativa. A integração dos conteúdos, mediada, por exemplo, por um docente em sala de aula, pode ser inspirada por uma racionalidade comunicativa habermasiana e, também, reflexiva e participativa. Em vista desse entendimento, o processo é concebido pela ação e a fala, pois são inseparáveis do conjunto de relações comunicativas na perspectiva da educação. É nessa perspectiva de desenvolvimento de ensino que se afirma Hermann:

\begin{abstract}
A formação do sujeito, enquanto tarefa básica da educação escolar vinculada à tradição, encontra formas de superação de um fundamento que entra em queda pela possibilidade de extrair uma racionalidade comunicativa das condições sociais. Trata-se de componentes estruturais do mundo da vida, cuja realização depende diretamente do processo educativo, capaz de produzir competência interativa e de autonomia. (1999, p.84).
\end{abstract}

Pode-se dizer que o processo de formação cultural do sujeito encontra reforços interativos na razão comunicativa, pois trata da cooperação entre os indivíduos. Nesse sentido, os meios de aprendizagem se manifestam no ambiente acadêmico e buscam credenciar a si e aos membros envolvidos. Isso caracteriza-se uma possibilidade de conjugação da ideia de liberdade e solidariedade colaborativa para uma educação, na perspectiva de emancipação social.

Por este viés, a linguagem comunicativa propõe uma relação intersubjetiva entre sujeitos que buscam a melhor argumentação. Trata-se de uma ação comunicativa, ou seja, não segue a padronização de uma ciência objetivista que define critérios, mas as próprias experiências comunicativas que possibilitam a (re)construção. É uma possibilidade na pluralidade de ideias, saberes, enfim, opiniões que norteiam a vida cotidiana humana, pois o conceito de razão comunicativa significa um processo que avalia todas as tendências 


\title{
Revista Ibero-Americana de Humanidades, Ciências e Educação \\ Produção e democratização do conhecimento na Ibero-América
}

possíveis de linguagem e compreensão. É nesse sentido que Habermas afirma:

\begin{abstract}
Em qualquer processo de entendimento do mais simples ao mais complicado, todos os partidos apóiam se num ponto de referência comum: o de um consenso possível, mesmo que esse ponto de referência seja esboçado a partir do respectivo contexto individual, porque ideias tais como verdade, racionalidade ou justificação desempenham a mesma função gramatical em toda a comunidade lingüística, mesmo que venham a ser interpretadas diferentemente e aplicadas com critérios distintos. (2002, p.175).
\end{abstract}

$\mathrm{Na}$ expectativa de um possível entendimento de consenso, está à ideia de "verdade" que não é assumida aqui como nas ciências objetivistas no processo de verificação de respectivas experiências, mas como um ideal que acate o melhor argumento racional do momento. É uma noção transitória e falível de referência fundamental no processo comunicativo capaz de buscar o entendimento em qualquer discurso, já que a racionalidade comunicativa não exerce a função de julgar, mas sim a de interpretar.

A ideia de "fundo" cultural em que se baseia a linguagem da ação comunicativa tem a perspectiva de consenso possível. Esse modo de agir delega a participação de todos os membros envolvidos no processo de compreensão. É um discurso racional que oportuniza o saber partilhado e fundamentado na ação comunicativa. Portanto, a noção de um entendimento, não é entendido na forma de uma razão estabelecida e solitária, mas na reconstrução democrática de saberes.

Nessa perspectiva, repensa a ideia de que isso não deixa de ser um processo de libertação metodológica crucial do modelo epistemológico, centrado no sujeito, em que a "passagem do paradigma da filosofia da consciência para o paradigma da filosofia da linguagem constitui um corte de igual profundidade" (HABERMAS, 2002, p.15). A comunicação pela linguagem, não só representa um avanço conceitual, mas significa principalmente uma mudança de postura social.

A razão adquire padrão de socialização mediante o uso da linguagem comunicativa. A ação comunicativa pode gerar, não somente possíveis processos de entendimento, mas também situações de desentendimento pelos sujeitos quando não há possibilidade de consenso; e nesse entendimento, o uso 


\section{Revista Ibero-Americana de Humanidades, Ciências e Educação \\ Produção e democratização do conhecimento na Ibero-América}

da linguagem possibilita a reconstrução de argumentos racionais na própria ação. Dessa maneira, a "orientação em função das operações da consciência é abandonada em proveito da orientação em função das objetivações do agir e do falar" (HABERMAS, 2002, p.26). A linguagem é ampliada mediante o processo de comunicação, pois é a afirmação de uma prática discursiva em direção ao entendimento possível na linguagem intersubjetiva² ${ }^{2}$.

A razão comunicativa, mediada pelo ideal de consenso, implica 0 processo intersubjetivo da linguagem e a intercompreensão que tem em vista a questão social. A crítica de Habermas à forma dominante da razão ocidental é vista como democrática, pois a pluralidade de "competência" e opinião pública permite que todos tenham possibilidades de fazer a partilha de saberes entre si na relação dialógica com o outro, desde que sejam respeitadas as suas respectivas normas.

Pode-se observar que o conceito expresso na ação comunicativa supõe uma condição que legitima esse processo, no intuito de estabelecer os interesses e possibilidades consensuais. A pretensão de validez torna afiançável a racionalidade intersubjetiva. A interação social busca o entendimento possível pautado na autocrítica, mesmo em condições de dissenso.

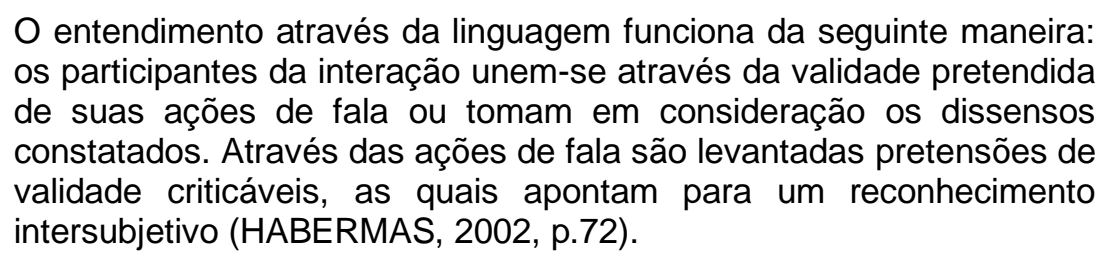

O processo de restauração discursiva das pretensões de validade mediante a linguagem intersubjetiva é vinculado à ideia de consenso refutável. A noção de possível acordo se reconhece também pelo pensamento crítico na compreensão de "verdade absoluta", pois é nessa condição que se pode estabelecer o argumento refutável que mantém a relação social e a teoria de

\footnotetext{
${ }^{2}$ Na perspectiva de Habermas, "a ideia de uma linguagem intersubjetiva é entendida como a opinião de vários sujeitos que indicam a possibilidade de consenso. Caso não seja possível o consenso, deve ser respeitada a opinião argumentativa que melhor responder aos objetivos propostos" (BLACKBURN, 1997, p.208).
} 


\section{Revista Ibero-Americana de Humanidades, Ciências e Educação \\ Produção e democratização do conhecimento na Ibero-América}

verdade na perspectiva em aberto.

De outra forma, seguindo o entendimento de Habermas, os atores agem estrategicamente na perspectiva da comunicação e não podem ser qualificados como possíveis geradores de entendimento intersubjetivo. Mas é possível que o agir estratégico possa ser uma alternativa, isto é, possa funcionar se o agir comunicativo fracassar. Nesse sentido, é uma opção, e não uma escolha como uma proposta realizável do discurso na comunicação.

Por este entendimento, Apel (1994) diz que é improvável de compreender a comunicação linguística a partir da interação estratégica, por causa da ação teleológica, pois é uma representação de uma ação calculada. Em vista dessa interpretação, Habermas indica outro sentido para o qual as ações podem ser comunicativas, já que:

As pessoas gostariam de agir comunicativamente, mas que elas são obrigadas a agir assim. Quando os pais querem educar os seus filhos, quando as gerações que vivem hoje querem se apropriar do saber transmitido pelas gerações passadas, quando os indivíduos e os grupos querem cooperar entre si, isto é, viver pacificamente com o mínimo de emprego de força, são obrigados a agir comunicativamente (1993, p.105).

Como se vê, o agir comunicativo é um processo que envolve a linguagem intersubjetiva e que deve ser compreendido como inerente à ação entre os sujeitos, sem coação. A "preservação" na tradição da história da educação pode ser realizada na perspectiva de continuidade na transmissão cultural, desde que seja interpretada e compartilhada entre os indivíduos em processo de cooperação mútua possível. Sendo assim, traz à tona as possibilidades de emancipação coletiva mediante as relações dialógicas entre sujeitos que colaboram entre si.

Um dos motivos significativos é apontar o empenho habermasiano em debater de modo argumentativo e racional. $O$ processo educacional pela linguagem comunicativa possibilita reconstruir alguma discussão que envolve a demanda da formação docente. A construção democrática do ideal de formação humana como princípio emancipativo nas práticas pedagógicas pode referenciar, auxiliar no contexto de ensino e da formação de professores. 


\section{Revista Ibero-Americana de Humanidades, Ciências e Educação \\ Produção e democratização do conhecimento na Ibero-América}

A cultura moderna cultua a noção do "eterno presente" nas dimensões culturais, intelectuais, estéticas, mas também nas relações entre educação e formação. Em diferentes épocas do ensino ocidental entende-se que não somente a filosofia se ampliou para novas concepções de mundo, mas também a própria pedagogia nas diversas formas. A perspectiva do ideal de formação humana emergiu do processo de reflexão em várias dimensões da vida social e cultural.

O pensamento pós-metafísico em Habermas é entendido na perspectiva de contribuir para o esclarecimento de uma educação ampla. Ao descentralizar a razão, propondo a pluralidade de culturas e ideias que procuraram articular a dinâmica de fazer experiência nas relações entre sujeitos, sociedade, identidade, homem/mulher e natureza. A virada pragmática da linguagem ocorrida na filosofia situou a razão em estruturas quase transcendentais.

A razão como linguagem possibilita a comunicação abrangente, pois 0 "lugar da relação reflexiva entre sujeito e objeto é ocupado por uma mediação comunicativa, no sentido amplo, dos sujeitos entre si" (HABERMAS, 2002a, p.44). O entendimento da relação subjetiva para a intersubjetividade possibilita a comunicação social como prática comunicativa. A linguagem comunicativa e intersubjetiva é regulada do ponto de vista daqueles que fazem as reivindicações, visando as transformações educativas e formativas.

Ao propor um discurso falível, as circunstâncias de argumentação projetaram um processo de racionalidade que abrange e respeita os múltiplos desenvolvimentos dos educadores. A reconstrução de argumentos mais solidários produz vivências de aprendizagens transformadoras da formação docente e consequentemente numa ação comunicativa ampla.

Nessa perspectiva, a formação docente encontra-se em constantes desafios que permeiam a sua prática pedagógica. Tornar as verdades irrefutáveis em refutáveis nos discursos acadêmicos, por meio do agir comunicativo e da linguagem, pode oferecer condições mais plausíveis para somar esforços contributivos na formação do educador atual. Esta possibilidade significa reavaliar o sentido da formação de professores, propondo uma 


\section{Revista Ibero-Americana de Humanidades, Ciências e Educação \\ Produção e democratização do conhecimento na Ibero-América}

reabilitação mediante a prática comunicativa de formar aprendizes de saberes sem pleitear a verdade absoluta. Nesse sentido, a posição conservadora da ação docente busca nada mais ou nada menos do que restaurar e renovar a formação e o ensino, no sentido plural e interdisciplinar, preocupando-se em expandir as possibilidades de aprendizagem docente. A recuperação do mundo cultural na perspectiva da pedagogia e da formação, no âmbito das ciências humanas, permite acreditar no potencial da linguagem intersubjetiva e comunicativa como condição possível para amenizar a lógica cientificista.

Contudo, na (re)construção de uma formação humana é importante perceber o que ocorreu no discurso do novo e do concreto, repensando como se dá a evolução abrangente do campo da cultura e do conhecimento. Tem-se que sem a compreensão crítica e hermenêutica do processo de reprodução da tradição da história da educação, não há possibilidade de contribuições no processo pedagógico atual, inclusive na formação docente. Com isso, o uso dos bons argumentos é o que mantém viva uma comunicação pedagógica que se mantém à base da partilha de saberes. Talvez a teoria da ação comunicativa auxilie a educação exatamente nesse ponto, ao propor a atenção dos educadores para a importância da tradição afeita à leitura dos clássicos, à disciplina teórica, ao compromisso crítico social, à visão pluralista e à ideia interdisciplinar que sobrevive na medida em que tiver as suas bases assentadas nos processos de linguagem e que convença os educadores a não abrir mão dessas instâncias.

\section{Referências bibliográficas}

APEL, Karl-Otto. Semiótica filosófica. Tradução de Julio Del Zan, Ricardo Maliandi y Dorando Michelini. Buenos Aires: Almagesto, 1994.

ARENDT, Hannah. Entre o passado e o futuro. Tradução de Mauro W. Barbosa de Almeida. São Paulo: Perspectiva, 1992.

BLACKBURN, Simon. Dicionário Oxford de Filosofia. Rio de Janeiro: Jorge Zahar Editor, 1997. BLEICHER, Josef. Hermenêutica Contemporânea. Lisboa: Edições 70, 2002. 


\section{Revista Ibero-Americana de Humanidades, Ciências e Educação \\ Produção e democratização do conhecimento na Ibero-América}

FORQUIN, J. C. Escola e cultura: as bases sociais e epistemológicas do conhecimento escolar. Tradução de Guacira Lopes Louro. Porto Alegre: Artmed, 1993.

HABERMAS, Jürgen. O Pensamento pós-metafísico. Tradução de Flávio Beno Siebeneichler. Rio de Janeiro: Tempo Brasileiro, 2002.

Discurso filosófico da modernidade. Tradução: Luiz Sérgio Repa e Rodnei Nascimento. São Paulo: Martins Fontes, 2002a

Teoría de la acción comunicativa, I. Versión castellana de Manuel Jiménez Redondo. Madrid: Taurus Humanidades, 2003.

Passado como futuro. Tradução Flávio Beno Siebeneichler. Rio de Janeiro: Tempo Brasileiro, 1993.

HERMANN, Nadja. Validade em Educação: intuições e problemas na recepção de Habermas. Porto Alegre: EDIPUCRS, 1999.

PINTO, F. Cabral. A Formação Humana no Projecto da Modernidade. Lisboa: Instituto Piaget, 1996.

ROUANET, Sérgio Paulo. As razões do iluminismo. São Paulo: Companhia das Letras, 1987.

WELLMER, A. Razón, utopia y la dialectica de la ilustración. In: GIDDENS, A. [et al].Habermas y la modernidad. Madrid: Cátreda, 1994. 